\title{
Bayesian learning in financial markets
}

\section{testing for the relevance of information precision in price discovery}

Hautsch, Nikolaus; Hess, Dieter

Publication date:

2004

Document version

Publisher's PDF, also known as Version of record

Citation for published version (APA):

Hautsch, N., \& Hess, D. (2004). Bayesian learning in financial markets: testing for the relevance of information precision in price discovery. Department of Economics, University of Copenhagen. 


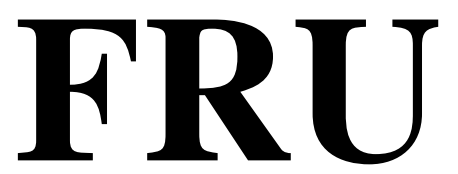

Finance Research Unit

\title{
Bayesian Learning in Financial Markets - Testing for the Relevance of Information Precision in Price Discovery
}

\author{
Nikolaus Hautsch and Dieter Hess
}

No. $2004 / 06$

Finance Research Unit

Institute of Economics

University of Copenhagen

http://www.econ.ku.dk/FRU 


\title{
Bayesian Learning in Financial Markets - Testing for the Relevance of Information Precision in Price Discovery*
}

\author{
Nikolaus Hautsch ${ }^{\dagger}$ and Dieter Hess ${ }^{\ddagger}$
}

September 2004

\begin{abstract}
An important claim of Bayesian learning and a standard assumption in price discovery models is that the strength of the price impact of unanticipated information depends on the precision of the news. In this paper, we test for this assumption by analyzing intra-day price responses of CBOT T-bond futures to U.S. employment announcements. By employing additional detail information besides the widely used headline figures, we extract release-specific precision measures which allow to test for the claim of Bayesian updating. We find that the price impact of more precise information is significantly stronger. The results remain stable even after controlling for an asymmetric price response to 'good' and 'bad' news.
\end{abstract}

Keywords: $\quad$ Bayesian learning; information precision; macroeconomic announcements; JEL classification: $\quad$ E44, G14

${ }^{*}$ For valuable comments we are grateful to Francis X. Diebold, Robert Engle, Oliver Fabel, Michael Fleming, Alexander Kempf, Christoph Memmel, Stefan Rünzi and David Veredas. This paper has also strongly benefited from comments of participants of the Market Microstructure and High Frequency Data Conference, Sandbjerg, August 2001, the 64th annual meeting of the "Verband der Hochschullehrer für Betriebswirtschaft", Munich, May 2002, the 10th Global Finance Conference, Frankfurt, June 2003, the third "Kölner Finanzmarktkolloquium", Cologne, November 2003, the 40th annual meeting of the Eastern Finance Association, Mystic, April, 2004, the Meeting of the European Financial Management Association, Zürich, June 2004, as well as from comments of workshop participants at the Universities of Copenhagen, Frankfurt, Karlsruhe, Konstanz, Cologne, St. Gallen and Ulm. Data on analysts' forecasts are obtained from Standard \& Poors MMS, announcement data from the Bureau of Labor Statistics. The authors gratefully acknowledge financial support by the Deutsche Forschungsgemeinschaft (DFG) within the Center of Finance and Econometrics (CoFE). Dieter Hess appreciates a grant by the DFG (project HE 3180/1).

${ }^{\dagger}$ University of Copenhagen, Institute of Economics, Studiestraede 6, DK-1455 Copenhagen, Denmark, tel: +453532 3022 email: nikolaus.hautsch@econ.ku.dk

${ }^{\ddagger}$ University of Cologne, Corporate Finance Seminar, Albertus-Magnus-Straße, D-50923 Cologne, Germany, tel: +49 (0)221 470 4360, email: hess@wiso.uni-koeln.de 


\section{Introduction}

The question of how fundamental information is incorporated into asset prices is one of the most important topics in financial economics. However, empirical research on price discovery is hindered by two major difficulties: First, information is hard to observe. In particular, researchers are confronted with the problem of recording the information flow accurately and of identifying and extracting relevant information driving prices. A second, and even more difficult issue, is to quantify how information is assessed by market participants. Naturally, the valuation of news depends on market participants' prior expectations and on how these expectations are built up based on the corresponding information sets.

Recent research has achieved considerable progress regarding the first problem. Using financial intraday data and headline information conveyed by scheduled macroeconomic releases, several studies ${ }^{1}$ were able to identify unanticipated information and to quantify the implied reaction of the price response. The general understanding by now is thus that unanticipated information has a strong and clearly identifiable effect on returns and price volatility.

Nevertheless, only little is known about how market participants react to information and how they build their beliefs regarding the meaning and the importance of surprising news. In this context, recent literature focusses on two major aspects. One branch emphasizes the importance of the state of the market in which the information arrives. For example, Veronesi (1999) showed within a rational expectations equilibrium framework that market participants may react quite differently to the same information - depending on their beliefs whether the economy is in a state of low or high growth. Conrad, Cornell, and Landsman (2002) find empirical evidence for such effects by analyzing firm-specific stock price reactions to earnings announcements in dependence of the aggregate level of the mar-

\footnotetext{
${ }^{1}$ See e.g. Ederington and Lee (1993), Balduzzi, Elton, and Green (1997), Fleming and Remolona (1999a), Andersen, Bollerslev, Diebold, and Vega (2002) or Hautsch and Hess (2002) among others.
} 
ket. An alternative aspect is stressed by the literature on Bayesian learning (see e.g. Kim and Verrecchia 1991, Kandel and Pearson 1995, or Veronesi 2000). This approach is based on the notion that market agents' reactions are strongly driven by their prior beliefs and the way they use new information in order to update these beliefs. In these models, the precision of new information (relative to the precision of information available before an announcement) is of particular importance. Therefore, one main implication of this literature is that price reactions are driven not only by the amount of unexpected information but also by its quality. In periods when released data is perceived to be more precise relative to prior information - a stronger price reaction should be observed to a given piece of unexpected information.

Until now these aspects have received comparatively little attention in empirical literature. Nevertheless, an important contribution in this field is provided by Krueger and Fortson (2003) who studied the influence of U.S. employment news on daily prices of Treasury bonds, but found only very limited evidence for an impact of the information precision. One reason for this result could be the fact that on a daily aggregation level, the measurement of price responses is overlaid by a lot of noise which makes the identification of such effects difficult. Another reason could be that the author's approximation of the information quality by a linear time trend which is assumed to capture the increasing precision of announcements over time is presumably too inexact.

To our knowledge no study has yet examined the claim of Bayesian updating using macroeconomic announcements and high-frequency market data. The goal of this paper is to fill this gap and to test the empirical relevance of the role of information precision on an intraday basis. By estimating the price response which is caused by the precision of information, we focus on the following two major research issues:

The first objective concerns the question of whether prices actually respond stronger to more precise news. I.e., is the price reaction stronger if the announced information is 
perceived to be more precise relative to the precision of the information available before the announcement? An answer to this question provides hints on whether market participants' valuation and perception of new information is in line with Bayesian learning mechanisms and whether the consideration of such effects significantly contributes to price discovery.

A second question in this paper concentrates on sign effects, i.e. asymmetries in the price response due to 'good' vs. 'bad' news. A wide range of papers are concerned with the question why prices respond stronger to 'bad' news than to 'good' news. For example, Fama and French $(1993,1996)$ explain this phenomenon by differences in the risk premium. Barberis, Shleifer, and Vishny (2002) and Daniel, Hirshleifer, and Subrahmanyam (1998) refer to aspects of investor psychology arising from arguments of behavioral finance. In contrast, Veronesi (1999) attributes these effects to the investor's uncertainty about the state of the economy. In order to preclude that asymmetries in the relative precision of information are driven by spurious correlations between the sign of the news and its precision, we analyze both sign and precision effects. In particular, we test whether prices react stronger to more precise news than to less precise news when the sign of news is explicitly taken into account. Such an analysis provides insights into the question whether information precision can be a further source for asymmetric price reactions.

As stated before, only limited empirical work has been undertaken so far in order to evaluate the role of information precision. One obvious reason for this deficiency is the lack of precision data, in particular the absence of precision measures for released information. Testing for the stronger price impact of more precise information clearly necessitates data on both precision of information available prior to a public announcement and precision of released information. However, both types of precision measures are rarely available at the same time. If analysts' forecasts are available, as for the headline figures of macroeconomic announcements, a proxy for the (im)precision of prior information can be obtained from 
the cross-sectional standard deviation of analysts' forecasts. ${ }^{2}$ Nevertheless, information on the precision of the released data is virtually unavailable, in particular if the accuracy of announcements varies over time. The unavailability of precision data is not only a problem researchers have to deal with. It often seems to be impossible for market participants as well to infer the precision of a given piece of information at the time of its release. ${ }^{3}$ Due to a lack of directly observable release-specific precision measures, market participants might try to use supplementary information to infer the accuracy of the announced data.

In order to extract and to quantify such precision measures, our empirical analysis focusses on announcements of the U.S. employment report. Besides the fact that this report has a profound impact on financial markets which is documented in various studies ${ }^{4}$, it offers a very interesting second source of information which becomes available at the same time as the widely awaited headline figures: the revision of the previous month's nonfarm payrolls figure. Since revisions reveal measurement errors in the previous reporting period, they may help traders to assess the reliability of the currently released headline figures, in particular if these measurement errors contain predictable components. Therefore we propose to extract a release-specific precision statistic by inspecting the history of (absolute) revisions. Technically speaking, the one-step-ahead forecast from a GARCH model fitted to the time series of revisions is used to approximate the (im)precision of the released information. This precision proxy allows us, in connection with the cross-sectional dispersion of analysts' forecasts, to construct a measure of the relative precision of announced and prior information.

\footnotetext{
${ }^{2}$ See, for example, Andersen, Bollerslev, Diebold, and Vega (2002) who use this measure to approximate investors' uncertainty.

${ }^{3}$ In some cases, researchers try to extract the perceived precision of the data from its impact on posterior beliefs. For example, Kandel and Zilberfarb (1999) compare inflation forecasts for a given period before and after a public announcement.

${ }^{4}$ Evidence for its extreme market impact is provided, for example, by Ederington and Lee (1993), Fleming and Remolona (1999c) or Bollerslev, Cai, and Song (2000). Therefore, the U.S. employment report is often referred to as the 'king of announcements' (see, e.g. Li and Engle 1998, or Andersen and Bollerslev 1998).
} 
Our empirical analysis is based on high-frequency data of the Chicago Board of Trade (CBOT) T-bond futures covering a twelve year period from January 1991 to December 2002. Applying the estimation approach described in detail in Hautsch and Hess (2002), we estimate the T-bond futures reactions in a 90-minute window around the monthly employment releases. Besides confirming the findings of previous studies that unanticipated headline information is processed within a few minutes, our analysis yields the following results: First of all, we document a strong asymmetry in the price response to precise vs. imprecise information, providing strong evidence in favor of the catalyzing effect of information precision. Second, in line with the empirical results of Conrad, Cornell, and Landsman (2002) for stocks, we find that the T-bond futures market reacts stronger to 'bad' news than to 'good' news. Disentangling these two asymmetric price reactions, we show that the catalyzing effect of information precision is not driven by a possibly asymmetric price response to 'good' and 'bad' news. In particular, we find that prices respond significantly stronger to precise 'bad' news than to imprecise 'bad' news. The same holds true for precise and imprecise 'good' news. Moreover, the remarkable robustness of the stronger price impact of more precise information across various alternative model specifications suggests that our relative precision estimate is a meaningful approximation of market participants' behavior in assessing the accuracy of unanticipated information which is provided by the employment report.

The remainder of this paper is organized as follows. The subsequent section delineates the role of information precision in determining the strength of the price impact. Section 3 illustrates the main information components in the employment report and explains how to construct appropriate precision estimates. Section 4 describes the high-frequency return data, outlines the estimation procedure, and presents the empirical results. Finally, Section 5 concludes. 


\section{The role of information precision}

Technical literature on information processing in financial markets addresses a wide range of different issues. Numerous studies cover aspects of the trading process, particularly the variance of price changes around news releases (e.g. Holthausen and Verrecchia 1988) or the link between trading volume and volatility (e.g. Holthausen and Verrecchia 1990, Kim and Verrecchia 1991a, b, Harris and Raviv 1993, Kandel and Pearson 1995, and Blume, Easley, and O'Hara 1994). A further branch of literature focusses on incentives to acquire private information before a public announcement (e.g. Verrecchia 1982, Kim and Verrecchia 1997 and Barlevy and Veronesi 2000), whereas another range of papers analyzes changes in the equity risk premium due to information arrival (Veronesi 2000). The different approaches provide important insights into the price adjustment to new information. Since these approaches typically build on a Bayesian updating framework to describe traders belief formation, a common result across various models is that the price reaction is driven primarily by the amount of unanticipated information. Moreover, the (relative) quality of information compared to prior information acts as a catalyst and determines the strength of this price reaction. In order to illustrate these effects in more detail, we outline the basic principles of Bayesian learning in a Gaussian framework.

Suppose that traders have homogeneous beliefs regarding some economic variable $X$ (e.g. the unemployment rate) before some public announcement is made. ${ }^{5}$ Let $g(X)$ denote these prior beliefs about $X$ and assume that they are normally distributed, i.e. $g(X)=N\left(\mu_{F}, 1 / \rho_{F}\right)$, where $\mu_{F}$ represents traders' mean forecast and $\rho_{F}$ the precision of this forecast defined as the inverse of the variance. Moreover, suppose that a public announcement is released which provides traders with a noisy estimate $\mu_{A}$ of $X$, but does not reveal the realization $X$ itself. We assume an additive error term structure,

\footnotetext{
${ }^{5}$ Note that $X$, like the corresponding forecasts and announcements, relate to one specific reporting month $t$, and hence should be indexed by $t$. For ease of exposition, we suppress this index here.
} 
i.e. $\mu_{A}=X+\varepsilon$, where $\varepsilon$ is a zero mean normally distributed error term with variance $\operatorname{Var}[\varepsilon]=1 / \rho_{A}$ and $\mathrm{E}[X \cdot \varepsilon]=0$. Hence the conditional probability density function (p.d.f) of $\mu_{A}$ given $X, f\left(\mu_{A} \mid X\right)$, is $N\left(X, 1 / \rho_{A}\right)$. Note that we abstract from information asymmetries and assume that all market participants know $\mu_{F}$ and $\rho_{F}$ before the announcement and that the public announcement reveals both $\mu_{A}$ and $\rho_{A}$.

Let $g\left(X \mid \mu_{A}\right)$ denote traders' posterior beliefs after observing the announced estimate $\mu_{A}$. According to Bayes rule, i.e.

$$
g\left(X \mid \mu_{A}\right)=\frac{f\left(\mu_{A} \mid X\right) g(X)}{\int_{-\infty}^{\infty} f\left(\mu_{A} \mid X\right) g(X) d X}
$$

and exploiting the normality of $\mu_{A}$ and $X$, the posterior beliefs are normally distributed with mean

$$
\mu_{P}:=\mathrm{E}\left[X \mid \mu_{A}\right]=\mu_{F} \frac{\rho_{F}}{\rho_{F}+\rho_{A}}+\mu_{A} \frac{\rho_{A}}{\rho_{F}+\rho_{A}}
$$

and precision

$$
\rho_{P}:=\operatorname{Var}\left[X \mid \mu_{A}\right]^{-1}=\rho_{F}+\rho_{A} .
$$

Hence the adjustment of market participants' mean beliefs induced by the public announcement, $\mu_{P}-\mu_{F}$, is obtained by

$$
\mu_{P}-\mu_{F}=\left(\mu_{A}-\mu_{F}\right) \frac{\rho_{A}}{\rho_{F}+\rho_{A}} .
$$

Thus the shift in traders' average beliefs is proportional to the deviation of the announcement $\mu_{A}$ from its corresponding mean forecast $\mu_{F}$. This is typically referred to as unanticipated information in an announcement or surprise $S$, i.e.,

$$
S:=\mu_{A}-\mu_{F}
$$

Moreover, the strength of this belief revision is also determined by the precision of the announcement, $\rho_{A}$, relative to the precision of posterior beliefs, $\rho_{P}=\rho_{F}+\rho_{A}$. 
Assume that the market price $P$ of some risky asset is proportional to traders' conditional expectations of $X$, i.e.,

$$
P= \begin{cases}\nu \cdot \mu_{F} & \text { before the announcement } \\ \nu \cdot \mu_{p} & \text { after the announcement }\end{cases}
$$

with $\nu$ denoting some constant. ${ }^{6}$ Then the change in market prices $\Delta P$ induced by a public announcement is given by

$$
\Delta P=\nu \cdot \pi \cdot S,
$$

where $\pi$ denotes the so-called 'price-response coefficient'

$$
\pi:=\frac{\rho_{A}}{\rho_{P}}=\frac{\rho_{A}}{\rho_{F}+\rho_{A}}
$$

that determines the strength of the price reaction dependent on the relative precision of the announced data compared to the precision of posterior beliefs.

From the above analysis the following empirically testable implications arise:

(i) Eq. (6) suggests that the immediate price change after an announcement is proportional to the amount of unanticipated information in an announcement. This implication is standard and has been tested in several previous studies, e.g. by Hardouvelis (1988), Dwyer and Hafer (1989), Fleming and Remolona (1999c) and Andersen, Bollerslev, Diebold, and Vega (2002), to name only a few.

(ii) From eq. (6) in connection with the price-response coefficient (eq. 7), it follows that the immediate price impact of a given surprise depends on the relative precision of the announcement compared to prior information. The price reaction is stronger (weaker) if the announced information is perceived to be more (less) precise relative to the precision of information available before the announcement. The two limiting

\footnotetext{
${ }^{6}$ For example, in the models of Kim and Verrecchia or Kandel and Pearson, traders directly receive signals on the asset's fair value. Then, $\nu=1$.
} 
cases emerge when $\rho_{F}=0$ or when $\rho_{A}=0$. In the first case, we observe a maximal price reaction due to the fact that prior information is completely unprecise. In the second case, the price response is zero because the announcement itself provides no new information.

Even though the above discussed model framework is rather simple, it is well able to capture the basic principle of Bayesian learning, i.e. that the magnitude of the price response is determined by the amount of unanticipated information and, at the same time, by the relative precision of information. This fundamental price effect of information can be found in various other learning models like for example approaches that model the frequently observed positive relation between volatility and trading volume. In the model of Kandel and Pearson (1995) traders interpret the released information differently, in Kim and Verrecchia (1991a, b) traders face different types of information asymmetries. While the much more sophisticated structure of these models is needed to establish a link between the magnitude of price changes and trading volume, the fundamental effect that relative information precision determines the strength of the price change remains virtually unchanged.

\section{Measuring the precision of information}

\subsection{Major information components in the U.S. employment report}

The profound price impact of unanticipated information in the U.S. employment report on various financial markets is well documented. ${ }^{7}$ While this report, which is released by

\footnotetext{
${ }^{7}$ Several studies provide strong evidence that unanticipated information in the employment report influences interest rates (e.g. Edison 1996, Becker, Finnerty, and Kopecky 1996, Fleming and Remolona 1999c, and Hautsch and Hess 2002), foreign exchange rates (e.g. Hardouvelis 1988, Payne 1996, Andersen, Bollerslev, Diebold, and Vega 2002), as well as stock prices (e.g. Boyd, Hu, and Jagannathan 2001). In addition, various studies document that the U.S. employment report influences the volatility of bond and foreign exchange markets (e.g. Ederington and Lee 1993, 1995, Crain and Lee, DeGennaro and Shrieves 1997, Andersen and Bollerslev 1998 Jones, Lamont, and Lumsdaine, 1998 Fleming and Remolona 1999c and Bollerslev, Cai, and Song) as well as bid-ask spreads (e.g. Fleming and Remolona 1999a and Balduzzi, Elton, and Green 2001) and trading volume (Fleming and Remolona 1999a, Franke and Hess 2000).
} 
the Bureau of Labor Statistics (BLS), provides a large amount of detailed information, both market participants and researchers focus their attention on a few so-called headline figures, in particular the nonfarm payrolls figure and the unemployment rate figure. Both figures provide market participants with a timely and comprehensive estimate of current economic activity. ${ }^{8}$ Moreover, they allow some inference about inflationary pressures, which might arise from a tightening labor market.

An important reason for researchers to focus on headline figures is the availability of analysts' forecasts. These forecasts allow to differentiate between the already anticipated part of a given piece of information and the unanticipated part. This is important because in efficient markets only unanticipated information has an impact on prices. ${ }^{9}$ Another reason for the widespread use of headline figures in empirical research is their dissemination via several news vendors within seconds. This comes quite close to an experimental situation where all traders simultaneously receive a certain piece of information and are able to act on it at the same time. As in previous studies of the employment report, we restrict our attention to the nonfarm payrolls figure and the unemployment rate. ${ }^{10}$

A particularly interesting feature of the employment report is the fact that the initially released nonfarm payrolls figure is revised in subsequent months. ${ }^{11}$ Table 1 provides an example. ${ }^{12}$ The announced nonfarm payrolls headline figure represents the change in the level of total nonfarm payrolls from month to month. The May 1999 employment report (last row in Table 1) released on June 4, 1999, 8:30 a.m. EST, announced a change in

\footnotetext{
${ }^{8}$ Nonfarm payrolls and unemployment rates are derived from two independent surveys (390,000 establishments and 50,000 households, respectively).

${ }^{9}$ Analysts' forecasts of macroeconomic figures are not always unbiased and efficient (see e.g. Becker, Finnerty, and Kopecky 1996). However, in particular for the employment report no systematic inefficiencies can be found (see e.g. Hess 2001).

${ }^{10}$ For example, Hardouvelis (1988), Dwyer and Hafer (1989) and Prag (1994) focus exclusively on unemployment rates, Fleming and Remolona (1999c) use nonfarm payrolls. Some authors employ both nonfarm payrolls and unemployment rates, like for example, Cook and Korn (1991), Edison (1996), Balduzzi, Elton, and Green (2001) and Andersen, Bollerslev, Diebold, and Vega (2002).

${ }^{11}$ To date and to our knowledge, only Krueger and Fortson (2003) make use of revision information. Using daily data, however, he finds no significant price impact of revisions.

${ }^{12}$ All tables and figures are provided in the appendix.
} 
nonfarm payrolls of 11 (thousand). ${ }^{13}$ Analysts had forecasted a change of 220 - this is the so-called 'consensus' forecast or the median of analysts' forecasts polled by MMS. Comparing the announced and the forecasted figure yields a surprise $S_{N F}$ of -209 . As in previous studies, this figure is used to measure the amount of unanticipated information in the released nonfarm payrolls figure. ${ }^{14}$ More interesting, however, is that along with this headline figure, a revision of the previous month's total nonfarm payroll figure is announced. For example, the May 1999 report shows that the preliminary April estimate had to be revised by 245 (i.e. from from the previously disclosed level of 127, 911 to 128, 156). Although the BLS estimation procedure accounts for a number of possible distortions of the sampling process, the data released in the previous month have to be revised, in particular to incorporate late responses and follow-up inquiries with nonrespondents. ${ }^{15}$ In addition, revisions reflect re-estimation of seasonal adjustment factors and alignments of the employment establishment survey-based estimates with the so-called full universe counts, i.e. the benchmark figures derived from administrative records on employees covered by unemployment insurance tax laws.

Note that revisions indicate problems in the sampling process, i.e. sampling errors in the previous month's data. Therefore, it seems reasonable to assume that market participants can learn something about the precision of the released data by analyzing revisions. This argument is set forth in the following section which shows how such a precision proxy can be constructed.

\footnotetext{
${ }^{13}$ This is the difference between the preliminary May estimate of the total number of nonfarm jobs (i.e. 128, 167 thousand) and the revised April estimate (i.e. 128, 156 thousand).

${ }^{14}$ The performance of analysts' forecasts of macroeconomic headline figures has been scrutinized, for example, by Pearce and Roley (1985), Hardouvelis (1988), Becker, Finnerty, and Kopecky (1996), Hess (2001) and Moersch (2001). Based on regressions of released figures $\left(A_{m}\right)$ on median forecasts $\left(F_{m}\right)$, i.e. $A_{m}=\alpha+\beta F_{m}$, where $m$ indexes monthly observations, the hypothesis of biased forecasts (i.e. $H_{0}$ : $\alpha=0, \beta=1$ ) can be rejected only for a few series, in particular for short sample periods. However none of the studies finds such deficiencies in nonfarm payrolls forecasts.

${ }^{15}$ For example, when a sampled firm goes out of business, most often it simply does not respond to the survey that month, rather than reporting zero employment. The information retrieved by a follow-up is often received too late to be incorporated into initial announcements. See "Technical Notes to Establishment Survey Data Published in Employment and Earnings" by the BLS.
} 


\subsection{Release-specific precision estimates}

While theoretical literature on the price impact of information emphasizes the importance of information precision, empirical research in this area is hindered by a lack of data regarding the precision of information, in particular the precision of the announced figures. The employment report offers a rare opportunity to study this subject since precision proxies can be obtained for both information available before an announcement and released data.

Firstly, the dispersion of analysts' forecasts before an announcement can be used to approximate the quality of pre-announcement information. Each Friday, Standard \& Poors Global Markets (MMS International) polls analysts' forecasts of macroeconomic figures to be released during the following week. ${ }^{16}$ Besides the widely used medians of forecasts, our data set contains the standard deviations of forecasts across analysts. Following Abarbanell, Lanen, and Verrecchia (1995), Mohammed and Yadav (2002), and Andersen, Bollerslev, Diebold, and Vega (2002), among others, we interpret the standard deviation of analysts' forecasts as a measure of cross-sectional dispersion of expectations. In our framework, it serves as a valuable proxy for the precision of prior information $\rho_{F}$, i.e. one of the two variables which determine the price-response coefficient $\pi$ in eq. (7). To be precise, $\hat{s}_{F, m}$ denotes the cross-sectional standard deviation of forecasts for the employment release for a particular month $m$. Then $\rho_{F, m}$ is estimated by $\hat{\rho}_{F, m}=1 / \hat{s}_{F, m}^{2}$.

In order to approximate the second input variable of the price-response coefficient, i.e. the precision of the released data $\rho_{A, m}$, we need a release-specific precision estimate of the announced headline figures. Unfortunately the employment report - like other macroeconomic reports - does not provide something like a survey-specific sample error estimate which would help traders to assess the quality of released data at the time of the an-

\footnotetext{
${ }^{16}$ According to MMS, survey responses are received over a 3 to 4 hour period every Friday morning via fax or phone. The results of the survey are published at about 1:30 pm EST.
} 
nouncement. Nevertheless, we suppose that traders try to obtain a substitute for such a precision estimate.

Particularly for the nonfarm payroll figure, a straightforward measure is obtained from the revision data. ${ }^{17}$ As described above, revisions indicate problems in the sampling process. However, a large revision in the currently released report only suggests that the quality of the previous month's headline figure was poor. In order to assess the quality of the currently announced data, traders would need to know to what extent this data will be revised next month, i.e. they would need some estimate of the magnitude of the subsequent revision. An important measure for the 'quality' of the surprise estimate, and thus the precision of the current headline figure, is the expected variance of the revision. When the expected revision variance is high, the reliability of the announced figure and, correspondingly, the relative precision of the announcement compared to prior information is low. In order to forecast the conditional mean and variance of revisions, we propose an ARMA-GARCH model fitted to the time-series of revisions (including the currently released one). ${ }^{18}$

For this purpose revision data for nonfarm payrolls since January 1980 was extracted from the original BLS reports. As shown in Figure 1, there is slight evidence for the existence of seasonal effects in absolute revisions. Such effects may be attributed, for example, to sampling problems arising from the students' job market entry in the summer months, as well as firms going out of business and firms creating new businesses. In order to account for these patterns, we estimate an ARMA-GARCH model, where we include a seasonality term in the conditional variance function. Hence, the estimated model is obtained by

$$
R_{N F, m}=c+\sum_{j=1}^{p_{1}} \phi_{1, j} R_{N F, m-j}+\sum_{j=1}^{q_{1}} \phi_{2, j} \varepsilon_{m-j}+\varepsilon_{m}, \quad \varepsilon_{m} \sim N\left(0, h_{m}\right)
$$

\footnotetext{
${ }^{17}$ Note that the second headline figure employed in this study, the unemployment rate, is not subject to monthly revisions.

${ }^{18}$ Clearly, besides forecasting the variance of the revision, traders would like to obtain its conditional mean. However, ex-ante one would expect that payrolls revisions are unpredictable, because otherwise the BLS would incorporate this information into their preliminary announcements. In fact, this notion is confirmed by the regression analysis reported below. While signed revisions are unpredictable, we find strong seasonal patterns in absolute revisions.
} 
with

$$
h_{m}=\omega+\sum_{j=1}^{p_{2}} \psi_{1, j} \varepsilon_{m-j}^{2}+\sum_{j=1}^{q_{2}} \psi_{2, j} h_{m-j}+s_{m},
$$

where $R_{N F, m}$ denotes the revision of the nonfarm payroll figure in month $m, h_{m}$ is the conditional variance of $\varepsilon_{m}$ and $s_{m}$ denotes a seasonality function which is specified on the basis of a Fourier series approximation as proposed by Andersen and Bollerslev (1998). Assuming a polynomial of degree $Q$, the non-stochastic seasonal trend term is specified as

$$
s_{m}=s\left(\delta^{s}, \bar{m}, Q\right)=\delta^{s} \cdot \bar{m}+\sum_{j=1}^{Q}\left(\delta_{c, j}^{s} \cos (j \cdot \bar{m} \cdot 2 \pi)+\delta_{s, j}^{s} \sin (j \cdot \bar{m} \cdot 2 \pi)\right),
$$

where $\delta^{s}, \delta_{c, j}^{s}$, and $\delta_{s, j}^{s}$ are the seasonal coefficients to be estimated and $\bar{m} \in[0,1]$ is a normalized time trend defined as the number of months from the beginning of a year until $m$ divided by 12 .

Estimation results based on alternative specifications are provided in Table 2. Columns (1) to (3) present parameter estimates for a simple $\mathrm{AR}(1)$ model, a $\operatorname{GARCH}(1,1)$ model and an AR(1)-GARCH(1,1) model. ${ }^{19}$ Models augmented with seasonality components are given in columns (4) and (5). The AIC criterion indicates a $\operatorname{GARCH}(1,1)$ model without any autoregressive term in the conditional mean function to be best specification. The highly significant GARCH parameter is close to one, and thus reveals a high persistence in the volatility process. Hence, forecasts of the revision variance are mainly dominated by the previous forecast, while the influence of the innovation is comparable low. Nevertheless, as indicated by a Lagrange Multiplier (LM) test against ARCH effects (Engle 1982) up to order 12 (last row in Table 2), models (1) to (3) explain only little of the heteroscedasticity in the revisions series since there is strong evidence for remaining autocorrelation in the series of squared residuals. As indicated by the AIC, accounting for seasonality effects in the variance function by including the above defined Fourier series improves the goodness-

\footnotetext{
${ }^{19}$ Various other ARMA and GARCH specifications were estimated as well. However, Table 2 displays only the best performing models under the AIC criterion.
} 
of-fit of the model considerably. This is confirmed by a likelihood ratio test on the jointsignificance of the Fourier series coefficients. Moreover, the ARCH-LM tests can no longer reject the null hypothesis of no autocorrelation in the squared residuals. These results show that seasonal effects actually play an important role and have to be considered explicitly.

The final selection of an appropriate forecasting model is performed on the basis of the AIC, which indicates specification (4) as the best model. Therefore, the precision of the nonfarm payrolls headline figure for month $m, \rho_{A, m}$, is estimated by $\hat{\rho}_{A, m}=\hat{h}_{m+1 \mid m}$, where $\hat{h}_{m+1 \mid m}$ denotes the one-step ahead forecast of the conditional revision variance. Together, the two proxy variables for precision of pre-announcement information and precision of announced data enable us to estimate the price-response coefficient $\pi_{m}$ in eq. (6) for nonfarm payrolls. On the basis of the estimated price response coefficient $\hat{\pi}_{m}$, we distinguish two types of employment announcements: 'precise' announcements (when a $\hat{\pi}_{m}$ equal to or above its sample median is observed) and 'imprecise' announcements (i.e. when the estimated $\hat{\pi}_{m}$ is below its sample median). ${ }^{20}$

\subsection{Measuring the average precision across headlines}

It should be noted that the Bureau of Labor Statistics (BLS) provides sampling error estimates of the different headline figures. These estimates may serve as a (time invariant) measure of the average precision of the released figures. According to the BLS, nonfarm payrolls have the smallest sampling errors, approximately $0.09 \%$. In contrast, the BLS estimates that the standard error of the unemployment rate is about $0.13 \% .{ }^{21}$ Comparing

\footnotetext{
${ }^{20}$ Note that Abarbanell, Lanen, and Verrecchia (1995) argue that the dispersion of analysts' forecasts may not fully capture investors' uncertainty before an announcement. Therefore, our proxy of prior information precision should be systematically too high and our price-response coefficient too low. However, since we are not primarily interested in the values of $\hat{\pi}$ itself, but instead use this proxy variable to group our observations into two categories ('precise' vs. 'imprecise' announcements), this bias should have no serious impact on our results.

${ }^{21}$ Bureau of Labor Statistics, Employment and Earnings, June 2000.
} 
these sampling error estimates, one would expect that the nonfarm payrolls figure provides the most reliable information, and hence has the strongest price impact on average.

\section{Empirical Results}

\subsection{Data}

We analyze CBOT T-bond futures returns in 2-minute intervals during a 90-minute window around employment releases, more precisely from 8:22 to 9:52 a.m. EST. This window is suggested on the one hand by the floor trading hours of the CBOT, which starts at 8:20 a.m. and on the other hand by the release of other macroeconomic announcements at 10:00 a.m. We use log returns calculated on the basis of the last trading price observed during a 2-minute interval. ${ }^{22}$ By using a twelve-year sample, i.e. January 1991 to December 2002, we obtain 128 announcement days after eliminating one day with an inadvertently early release in November 1998 and 15 days with overlapping announcements. ${ }^{23}$ Intraday data on CBOT T-Bond futures are obtained from the Futures Industry Institute. We focus on the front month contract, i.e. the most actively traded contract among the nearby and second nearby contracts.

Data on analysts' forecasts, in particular medians and standard deviations of forecasts, are obtained from Standard \& Poors MMS. Initially released non-revised headline figures as well as revisions are extracted from the original monthly BLS releases. ${ }^{24}$ Following previous studies, we measure the unanticipated information component in these two headline figures

\footnotetext{
${ }^{22}$ For example, the return associated with the employment release, in this case the 8:30-8:32 return, is computed from the last price before the 8:30 announcement and the last price before 8:32. See Hautsch and Hess (2002) for further details.

${ }^{23}$ In the analyzed period, we recorded one announcement of the GDP report at the same time, six Personal Income releases and eight Leading Indicators announcements. Although most of these reports are of minor importance (see e.g. Fleming and Remolona 1999c) all of these days are eliminated to avoid interference. Moreover, we eliminated one day with an inadvertently early release (see e.g. Fleming and Remolona 1999b). Note, however, that retaining these 16 observations does not change our results substantially.

${ }^{24}$ Medians and standard deviations of analysts forecasts are proprietary MMS data. Historical time series of initially released headline figures and revisions are available from different sources, for example, the BLS's 'Monthly Labor Review'.
} 
by the deviation of the announced figures from the medians of corresponding analysts' forecasts. Most previous studies use standardized surprises, i.e. for each headline, surprises are divided by their corresponding sample standard deviation. ${ }^{25}$ In order to exploit the fact that both figures are closely related and to facilitate a comparison of the price impact across headline figures, we measure surprises in both figures in terms of percentage changes. Precisely, nonfarm payrolls surprises are defined as the deviation of the announced number of new nonfarm payrolls from the median of analysts' forecasts divided by the number of total nonfarm payrolls in the previous month (times 100). The unemployment rate figure is already given in percentage points (i.e. the change of the overall unemployment rate from month to month).

\subsection{Estimation approach}

To investigate the effects of variations in the quality of information, we model the log returns using an ARMA specification which is augmented by appropriate explanatory variables. In order to account for (conditional) heteroscedasticity, we include ARCH terms and seasonality variables in the conditional variance function. Hence, we assume the following process for 2-minute log returns:

$$
r_{t}=c+\sum_{j=1}^{p_{1}} \phi_{1, j} r_{t-j}+\sum_{j=1}^{q_{1}} \phi_{2, j} \varepsilon_{t-j}+x_{t}^{\prime} \beta+\varepsilon_{t}, \quad \varepsilon_{t} \sim N\left(0, h_{t}\right)
$$

with

$$
h_{t}=\omega+\sum_{j=1}^{p_{2}} \phi_{1, j} \varepsilon_{t-j}^{2}+s_{t} .
$$

Note that $t$ indexes the 2-minute intervals around the release of the employment report for month $m$, e.g. $\mathrm{t}=0$ indicates the interval following immediately after the announcement, i.e. 8:30 - 8:32 a.m. EST and $\mathrm{t}=1$ the 8:32 - 8:34 interval. The vector $x_{t}$ consists of explanatory variables in the conditional mean function including the surprise and revision

\footnotetext{
${ }^{25}$ See, for example, Andersen, Bollerslev, Diebold, and Vega (2002) or Hautsch and Hess (2002).
} 
variables described above (see Section 4.3) while $\beta$ is the corresponding coefficient vector. The seasonality function $s_{t}$ in the conditional variance function accounts for heteroscedasticity due to (deterministic) baseline patterns of the volatility around announcements (see e.g. Hautsch and Hess, 2002) and is specified in terms of a flexible Fourier form (see eq. 10) based on the 90-minute time interval.

In contrast to Andersen and Bollerslev (1998), we do not include any daily GARCH components in the variance equation. Since we focus on narrow time windows around monthly announcements instead of analyzing a 24-hour-7-day period it seems reasonable to ignore the daily GARCH component. Nevertheless, there might be a heteroscedasticity component which is ignored here and it is therefore crucial to use robust estimates of the covariance matrix of the parameters. Thus, the AR-ARCH model is estimated by quasi maximum likelihood (QML), where the standard errors are computed based on the Bollerslev and Wooldridge (1992) estimator of the variance covariance matrix.

\subsection{Estimation results: Information precision and the strength of the price response}

The central question of our paper is whether the precision of information determines the strength of the price impact of unanticipated information, as it is suggested by the standard Bayesian learning framework. We investigate this issue by testing whether the estimated coefficients capturing the price impact of 'precise' information are significantly different from those coefficients capturing the price impact of 'imprecise' information. To analyze the robustness of our results we estimate several alternative specifications of eq. (11) and (12).

Estimation results for five different specifications of eq. (11) are given in Table 3 . The lag order of the individual autoregressive components is chosen according to the AIC and reveals an $\mathrm{AR}(2)-\mathrm{ARCH}(3)$ specification as the preferred model. The conditional 
mean function includes variables accounting for a surprise in nonfarm payrolls $S_{N F}$ and in unemployment rates $S_{U N}$ as well as for the revision of the previously released nonfarm payrolls figure $R_{N F}$. In order to account for the timing of the impact of announcements, these variables are interacted with time dummies. For instance, $S_{N F, t}$ takes on the value of the surprise variable $S_{N F}$ in the 8:30 - 8:32 interval, i.e. the 2-min interval following immediately the release of the employment report, and 0 otherwise. Hence the estimated coefficient of $S_{N F, t}$ captures the immediate price impact of a surprise in nonfarm payrolls. In addition, $S_{N F, t+1}$ accounts for a 'postponed' price impact, i.e. in the interval 8:32 8:34. $S_{N F, t-1}$ captures information leakage effects, i.e. a price impact in the interval 8:28 $-8: 30 .{ }^{26}$

As a starting point, model (1) provides a specification which does not account for the relative precision of unanticipated information. The results confirm several major findings of previous studies. ${ }^{27}$ Firstly, the large values of the highly significant coefficients of $S_{N F, t}$ and $S_{U N, t}$ show that surprising headline information has a strong and significant impact on intraday returns. Secondly, markets process unanticipated headline information very rapidly. As indicated by the insignificant coefficient of $S_{U N, t+1}$ and the relative small coefficient of $S_{N F, t+1}$ (as compared to $S_{N F, t}$ ), the price reaction is completed within a two to four minutes. ${ }^{28}$ Thirdly, the directions of observed price reactions are consistent with standard theory: T-bond futures prices rise in response to 'good' news from the inflation front, i.e. a lower than expected increase in nonfarm payrolls and a higher than expected unemployment rate. Fourthly, a comparison of the magnitude of the coefficients of $S_{N F, t}$ and $S_{U N, t}$ shows that the nonfarm payrolls figure has the strongest price impact.

\footnotetext{
${ }^{26}$ However, leakage effects are very unlikely given the strict lock-up conditions governing the release of the employment report. See, for example, Ederington and Lee 1993, 1995 or Fleming and Remolona 1999a, c for a detailed description of the dissemination procedure.

${ }^{27}$ See, for example, Becker, Finnerty, and Kopecky (1996), Balduzzi, Elton, and Green (2001), Fleming and Remolona (1999a, b, c), or Hautsch and Hess (2002) for bond markets and Almeida, Goodhart, and Payne (1998) or Andersen, Bollerslev, Diebold, and Vega (2002) for foreign exchange markets.

${ }^{28}$ We also analyzed the influence of surprises in the following intervals, in particular $t+2, \ldots, t+5$, but no significant coefficient estimates were obtained.
} 
Extending previous studies, we also include revisions of the previously released nonfarm payroll figure into the analysis, in particular $R_{N F, t-1}, R_{N F, t}$ and $R_{N F, t+1}$. However, none of these coefficients is statistically significant. This creates the impression that market participants ignore revisions.

Overall, model (1) strongly confirms previous results of a consistent, sharp, and rapid price reaction to unanticipated information. However, it does not provide an answer to the question of whether information precision determines the strength of the price reaction, since it does not account for the differences of the relative precision of unanticipated information over time. Nevertheless, it allows us to compare the price impact of headline figures with different average precisions (see section 3.3). According to the BLS, the average sampling error of the nonfarm payrolls figure is smaller (i.e. 0.09\%) than the sampling error of the unemployment rate figure (i.e. $0.13 \%) .{ }^{29}$ Hence we would expect the more precise nonfarm payrolls figure to have a stronger price impact on average. In fact, the estimated coefficients of $S_{N F, t}$ is about three times as high as the coefficient of $S_{U N, t} \cdot{ }^{30}$ This is confirmed on the basis of a one-sided likelihood ratio (LR) test of the null hypothesis that a surprise in the unemployment figure moves prices more than a comparable surprise in the nonfarm payrolls headline, which is rejected at the $1 \%$ level. Note that the null hypothesis is $H_{0}: \beta_{4} \geq-\beta_{7}$, since a higher than expected nonfarm payrolls figure $\left(S_{N F}>0\right)$ should have a negative return impact while a higher than expected unemployment rate $\left(S_{U N}>0\right)$ should have a positive return impact. The result of this LR test may be interpreted as a first piece of evidence in favor of the claim of Bayesian learning that more precise information should have a stronger price impact.

In order to investigate the effects of release-specific precision measures, we extend model (1)

\footnotetext{
${ }^{29}$ See, for example, BLS, Employment and Earnings, June 2000.

${ }^{30}$ Surprises in both the nonfarm payrolls and the unemployment headline figure, $\left(S_{N F, t}\right.$ and $S_{U N, t}$, resp.) indicate unanticipated changes in (un)employment, however, based on two independent surveys. Nevertheless, since we measure surprises in both headline figures in percentage points, the magnitudes of the estimated coefficients are directly comparable.
} 
by including interaction variables which account for differences in information precision across nonfarm payroll announcements (columns (2) to (4)). According to eq. (6) the strength of the price reaction is determined by the relative precision of the announced data compared to the pre-announcement information, i.e. the price-response coefficient at month $i, \hat{\pi}_{m}=\hat{\rho}_{A, m} /\left(\hat{\rho}_{F, m}+\hat{\rho}_{A, m}\right)$. As outlined above, a precision estimate of the announced information $\left(\hat{\rho}_{A, m}\right)$ is derived from the variance forecast based on the time series of observed revisions (including the currently announced revision of the previously released headline figure) while the precision of the pre-announcement information $\left(\hat{\rho}_{F, m}\right)$ is obtained from the dispersion of analysts' forecasts. According to eq. (6), a high value of $\hat{\pi}_{m}$ should result in a more pronounced belief revision and hence in a stronger price reaction. In order to test this implication we split up the variable $S_{N F, t}$ by introducing an interaction variable which accounts for high vs. low values of $\pi_{m}$. To be precise, the dummy variable $D^{\pi}$ high takes on the value 1 if the proxy for the price-response coefficient $\hat{\pi}_{m}$ at month $m$ is higher than the sample median of $\hat{\pi}_{m}$, and 0 otherwise. $D^{\pi}$ low equals 1 if $\hat{\pi}_{m}$ is lower or equal than the sample median, i.e. $D^{\pi \text { low }}:=1-D^{\pi \text { high }}$.

The large difference between the estimated coefficients strongly supports the notion that the relative precision determines the strength of the price impact. The coefficient $\beta_{4}{ }^{h}$ associated with $D^{\pi h i g h}$ is almost $50 \%$ larger than $\beta_{4}{ }^{\ell}$ associated with $D^{\pi \text { low }}$. This suggests that 'precise' announcements move prices much more than 'imprecise' information. In fact, on the basis of a one-sided LR test, the null hypothesis that imprecise nonfarm payrolls surprises have a stronger price impact can be rejected at the $1 \%$ level. Note that due to the negative sign of $\beta_{4}$ the null hypothesis becomes $H_{0}: \beta_{4}{ }^{\ell} \leq \beta_{4}{ }^{h}$. In addition, a comparison of the goodness-of-fit of model (1) and (2) based on the AIC suggests that the inclusion of precision dummies leads to an improvement of the model's goodness-of-fit.

In model (2) we allow solely for a precision dependent asymmetric price response to nonfarm payrolls in the first 2-min interval by interacting only $S_{N F, t}$ with the above defined 
'precision' dummy variables. By also interacting $S_{N F, t+1}$ in model (3) we explore whether this asymmetric price response carries on to the second interval. In fact, the price impact of precise information is significantly stronger than of imprecise information in the second 2-min interval, too $\left(H_{0}: \beta_{5}^{\ell} \leq \beta_{5}{ }^{h}\right.$ is rejected at the $5 \%$ level $)$.

\subsection{Quality of information vs. sign effects?}

An alternative candidate to explain asymmetric price reactions is the so-called sign effect, i.e. a stronger price response to 'bad' than to 'good' news. Several models imply such asymmetries in the price response. For example, Veronesi (1999) shows in a rational expectations framework, in which investors are confronted with uncertainty about the state of the economy, that 'bad' news have a stronger impact on stock prices than 'good' news, in particular if this 'bad' news occurs in 'good' times. Comparable results are obtained in the behavioral frameworks of Barberis, Shleifer, and Vishny (2002) and Daniel, Hirshleifer, and Subrahmanyam (1998).

It might be argued that without a more detailed analysis we cannot preclude that our finding of an asymmetric price response to more precise news stems from a spurious correlation between the precision and the sign of information. For example, it could be possible that within our sample period 'bad' news came with a higher precision than 'good' news. In order to account for both sign and precision effects, we extend the previous analysis. We want to test in particular whether prices react stronger to more precise 'bad' news than to less precise 'bad' news, and in addition, whether they respond stronger to more precise 'good' news than to less precise 'good' news.

To perform this test, we re-estimate the parsimonious model (4) given in Table 3 and introduce another dummy variable which accounts for the sign of non-farm payrolls surprises. Estimation results are documented in Table 4. The variables capturing the immediate price impact of unanticipated information in the nonfarm payrolls figure $\left(S_{N F, t}\right)$ are in- 
teracted with dummy variables which indicate whether a surprise in this headline figure provides 'good' news for the bond market (i.e. $D^{\text {good }}=1$ if $S_{N F}<0$ ) or 'bad' news (i.e. $D^{b a d}=1-D^{g o o d}$ ). In other words, we split up the regressor $S_{N F, t}$ into a variable accounting for positive surprises and a separate variable for negative surprises. Thus, the coefficients $\beta_{4}{ }^{, b}$ (and $\left.\beta_{4}{ }^{\circ}, g\right)$ capture the immediate impact of 'bad' ('good') news, i.e. a higher (lower) than expected nonfarm payrolls figure.

In order to facilitate a comparison, model (5) provides a parsimonious version of model (1). This specification ignores both the precision and the sign of $S_{N F, t}$. Model (6), which is identical to model (4), accounts for the precision effect but not for the sign effect. In contrast, model (7) ignores the precision of information but accounts for its sign. Finally, model (8) accounts for both effects. In line with the results of Conrad, Cornell, and Landsman (2002) for the stock market, the estimated coefficients for model (7) indicate that 'bad' news has a stronger (negative) price impact than 'good' news. In fact, the null hypothesis that $\beta_{4}{ }^{b} \geq \beta_{4}{ }^{g}$ can be rejected at the $1 \%$ significance level. Moreover, the difference in the impact of 'good' and 'bad' news is very similar to the difference in the impact of precise and imprecise news (specification 6). Hence, from the comparison of models (6) and (7) we cannot conclude whether asymmetries in the price response are solely due to a 'good' versus 'bad' news effect or a 'precise' versus 'imprecise' news effect or whether both effects are present. Therefore, we interact the 'bad' and 'good' news variables with the precision dummies in model (8). This analysis clearly shows that both effects are at work at the same time.

On the one hand, the price impact of precise 'bad' news is stronger than the impact of precise 'good' news, i.e. $\beta_{4}{ }^{h, b}<\beta_{4}{ }^{h, g}$ (the same holds true for imprecise 'bad' and 'good' news, i.e. $\left.\beta_{4}^{\ell, b}<\beta_{4}^{\ell, g}\right)$. This is confirmed by a onesided LR test on the joint hypothesis that the price impact of 'bad' news (ei- 
ther precise or imprecise) is not larger than the price impact of 'good' news, i.e., $H_{0}: \beta_{4}{ }^{h, b} \geq \beta_{4}{ }^{h, g}, \beta_{4}^{\ell, b} \geq \beta_{4}^{\ell, g}$. This hypothesis can be rejected at the $1 \%$ level.

On the other hand, similar differences can be found between precise and imprecise news. The price impact of precise 'bad' news is stronger than the impact of imprecise 'bad' news, i.e. $\beta_{4}{ }^{h, b}<\beta_{4}^{\ell, b}$ (the same holds true for precise and imprecise and 'good' news, i.e. $\left.\beta_{4}{ }^{h, g}<\beta_{4}{ }^{\ell, g}\right)$. In fact, on the basis of a one-sided LR test, the hypothesis that the more precise news does not have a stronger price impact after controlling for an asymmetric price response to 'bad' vs. 'good' news (i.e. $H_{0}: \beta_{4}{ }^{h, b} \geq \beta_{4}{ }^{\ell, b}, \beta_{4}{ }^{h, g} \geq \beta_{4}{ }^{\ell, g}$ ) is rejected at the $1 \%$ level as well.

Overall, these results provide strong evidence in favor of the claim of Bayesian learning that the quality of information plays an important role in determining its price impact. Prices respond stronger to more precise news. Although, we find evidence for a sign effect in the bond market which does not explain the precision effect. Thus, asymmetries in the price response to unanticipated information are driven by differences in the (relative) precision and by the sign of this information.

\section{Conclusion}

The theory of belief formation in financial markets suggests that the quality of information determines the strength of the price reaction to a given piece of unanticipated information. Empirical research on the price reaction to information has focused on U.S. macroeconomic announcements since they allow for a fine measurement of the information flow. Unfortunately, due to the unavailability of release-specific data on the precision of information, little evidence in favor of the link between the strength of the price reaction and the quality of information is available. The main objective of this paper is to fill this gap left in the empirical literature. By utilizing additional detail information being released with the headline figures of the employment report, i.e. revisions of previously announced 
figures, we are able to extract a measure of the quality of the released data. Together with the cross-sectional standard deviations of analysts' forecasts we obtain an approximate measure for the release-specific relative quality of the nonfarm payrolls headline figure, which is the most influential information component in the employment report. Since this precision measure is based exclusively on information which is available at the time of an announcement, we assume that it provides a reasonable approximation of the quality of released information on which market participants can base their trading decisions.

The empirical analysis is based on high-frequency data from the CBOT T-bond futures. By using the proposed precision proxies, we find significant evidence in favor of the claim of Bayesian learning that the quality of information acts as a catalyst, i.e. prices respond stronger to more precise news. Our results suggest that traders try to compensate for the lack of official release-specific sample error estimates by extracting release-specific precision signals from additional information related to the widely awaited headline figures.

Analyzing the robustness of this result, the stronger price impact of more precise news remains unchanged, even if we control for the asymmetric price reaction due to 'good' or 'bad' news. I.e. precise 'bad' ('good') news lead to stronger downward (upward) price movements than imprecise 'bad' ('good') news. Hence, asymmetries in price responses to news are driven by both the precision and the sign of information. 


\section{References}

Abarbanell, J. S., W. N. Lanen, and R. E. Verrecchia (1995): "Analysts' forecasts as proxies for investor beliefs in empirical research," Journal of Accounting and Economics, 20(1), 31-60.

Almeida, A., C. A. E. Goodhart, and R. Payne (1998): "The effects of macroeconomic news on high frequency exchange rate behavior," Journal of Financial and Quantitative Analysis, 33(3), 383-408.

Andersen, T. G., T. Bollerslev, F. X. Diebold, and C. Vega (2002): "Micro Effects of Macro Announcements: Real-Time Price Discovery in Foreign Exchange," Discussion Paper 8959, NBER, Cambridge, MA.

Andersen, T. G., and T. Bollerslev (1998): "Deutsche Mark-Dollar volatility: intraday activity patterns, macroeconomic announcements and longer run dependencies.," Journal of Finance, 53(1), 219-265.

Balduzzi, P., E. J. Elton, and C. Green (1997): "Economic news and the yield curve: Evidence for the U.S. Treasury market," Discussion paper, New York University, Oktober 1997.

- (2001): "Economic news and bond prices: Evidence from the U.S. Treasury market," Journal of Financial and Quantitative Analysis, 36(4), 523-543.

Barberis, N., A. Shleifer, and R. W. Vishny (2002): "A model of investor sentiment," Journal of Financial Economics, 49(3), 307-347.

Barlevy, G., ANd P. Veronesi (2000): "Information acquisition in financial markets," Review of Economic Studies, 67(230), 79-90.

Becker, K. G., J. E. Finnerty, and K. J. Kopecky (1996): "Macroeconomic news and the efficiency of international bond futures markets," Journal of Futures Markets, $16(2), 131-145$. 
Blume, L., D. Easley, and M. O'Hara (1994): "Market statistics and technical analysis: The role of volume," Journal of Finance, 49(1), 153-181.

Bollerslev, T., J. Cai, and F. M. Song (2000): "Intraday periodicity, long memory volatility, and macroeconomic announcement effects in the US Treasury bond market," Journal of Empirical Finance, 7(1), 37-55.

Bollerslev, T., And J. Wooldridge (1992): "Quasi-Maximum Likelihood Estimation and Inference in Dynamic Models with Time Varying Covariances," Econometric Reviews, 11(2), 143-172.

Boyd, J. H., J. Hu, and R. Jagannathan (2001): "The Stock Markets Reaction to Unemployment News: Why Bad News Is Usually Good For Stocks," Discussion Paper 8092, NBER, Cambridge, MA.

Conrad, J., B. Cornell, and W. R. Landsman (2002): "When Is Bad News Really Bad News?," Journal of Finance, 57(6), 2507-2533.

CoOK, T., AND S. Korn (1991): "The reaction of interest rates to the employment report: The role of policy anticipations," Economic Review, Federal Reserve Bank of Richmond, $77(5)$.

Crain, S. J., And J. H. LeE (1995): "Intraday volatility in interest rate and foreign exchange spot and futures markets," Journal of Futures Markets, 15(4), 395-421.

Daniel, K., D. Hirshleifer, and A. Subrahmanyam (1998): "Investor psychology and security market under- und overreactions," Journal of Finance, 53, 1839-1885.

DeGennaro, R. P., and R. E. Shrieves (1995): "Public information releases, private information arrival and volatility in the foreign exchange market," Journal of Empirical Finance, 4(4), 295-315.

Dwyer, G.-P., And R. W. HAfer (1989): "Interest rates and economic announcements," Federal Reserve Bank of St. Louis Review, 71(2), 34-46. 
Ederington, L. H., And J. H. Lee (1993): "How markets process information: News releases and volatility," Journal of Finance, 48(4), 1161-1191.

- (1995): "The short-run dynamics of the price adjustment to new information," Journal of Financial and Quantitative Analysis, 31(1), 117-134.

EDISON, H. J. (1996): "The reaction of exchange rates and interest rates to news releases," Discussion Paper 570, Board of Governors of the Federal Reserve System.

ENGLE, R. F. (1982): "A general approach to Lagrange multiplier model diagnostics," Journal of Econometrics, 20(1), 83-104.

FAma, E. F., And K. R. French (1993): "Common risk factors in the returns on stocks and bonds," Journal of Financial Economcis, 33, 3-56.

(1996): "Multifactor explanations of asset pricing anomalies," Journal of Finance, $51,55-84$.

Fleming, M. J., and E. M. Remolona (1999a): "Price formation and liquidity in the U.S. Treasury market: The response to public information," Journal of Finance, 54(5), 1901-1915.

- (1999b): "The term structure of announcement effects," Discussion paper, Federal Reserve Bank of New York.

(1999c): "What moves the bond market," Journal of Portfolio Management, $25(4), 28-38$.

Franke, G., And D. Hess (2000): "The impact of scheduled news announcements on T-bond and Bund futures trading," in Institutional Arrangements for Global Economic Integration, ed. by H.-J. Vosgerau, pp. 337-366, MacMillan, London.

Hardouvelis, G. A. (1988): "Economic news, exchange rates, and interest rates," Journal of International Money and Finance, 7(1), 23-35. 
Harris, M., ANd A. RAviv (1993): "Difference of opinion make a horse race," Review of Financial Studies, 6(3), 473-506.

Hautsch, N., And D. Hess (2002): "The processing of non-anticipated information in financial markets: Analyzing the impact of surprises in the employment report," European Finance Review, 6, 133-161.

Hess, D. (2001): "Information processing in financial markets," habilitation thesis, University of Konstanz.

Holthausen, R. W., and R. E. Verrecchia (1988): "The effect of sequential information releases on the variance of price changes in an intertemporal multi-asset market," Journal of Accounting Research, 26(1), 82-106.

- (1990): "The effect of informedness and consensus on price and volume behavior," The Accounting Review, 65(1), 191-208.

Jones, C., O. Lamont, and R. Lumsdaine (1998): "Macroeconomic news and bond market volatility," Journal of Financial Economics, 47(3), 315-337.

Kandel, E., And N. D. Pearson (1995): "Differential interpretation of public signals and trade in speculative markets," Journal of Political Economy, 103(4), 831-872.

Kandel, E., And B.-Z. Zilberfarb (1999): "Differential interpretation of public signals and trade in speculative markets," Review of Economics and Statistic, 81(2), 217-226.

KIM, O., AND R. VerReCCHIA (1991a): "Market reaction to anticipated announcements," Journal of Financial Economics, 30(2), 273-309.

(1991b): "Trading volume and price reactions to public announcements," Journal of Accounting Research, 29(2), 302-321.

(1997): "Pre-announcement and event-period private information," Journal of Accounting and Economics, 24(3), 395-419. 
Krueger, A. B., and K. N. Fortson (2003): "Do Markets Respond More to More Reliable Labor Market Data? A Test of Market Rationality," Journal of the European Economic Association, 1, 931-957.

Li, L., AND R. F. ENGLE (1998): "Macroeconomic announcements and volatility of treasury futures," Discussion Paper 98-27, Department of Economics, University of California, San Diego Discussion Paper 98-27.

Moersch, M. (2001): "Predicting market movers: A closer look at consensus forecasts," Business Economics, 36(2), 24-29.

Mohammed, S. R., And P. K. Yadav (2002): "Quality of Information and Volatility Around Earnings Announcements," Discussion paper, University of Strathclyde.

PAYNe, R. (1996): "Announcement effects and seasonality in the intraday foreign exchange market," Discussion paper, London School of Economics Financial Market Group.

Pearce, D. K., And V. V. Roley (1985): "Stock Prices and Economic News," Journal of Business, 58.

PRAG, J. (1994): "The response of interest rates to unemployment rate announcements: Is there a natural rate of unemployment," Journal of Macroeconomics, 16(1), 171-184.

Veronesi, P. (1999): "Stock market overreaction to bad news in good times: A rational expectations equilibrium model," Review of Financial Studies, 12(5), 975-1007.

(2000): "How does information quality affect stock returns," Journal of Finance, $55(2), 807-837$.

VerReCCHIA, R. E. (1982): "Information acquisition in a noisy rational expectations economy," Econometrica, 50(6), 1415-30. 
Figure 1: History of nonfarm payrolls revisions since 1980

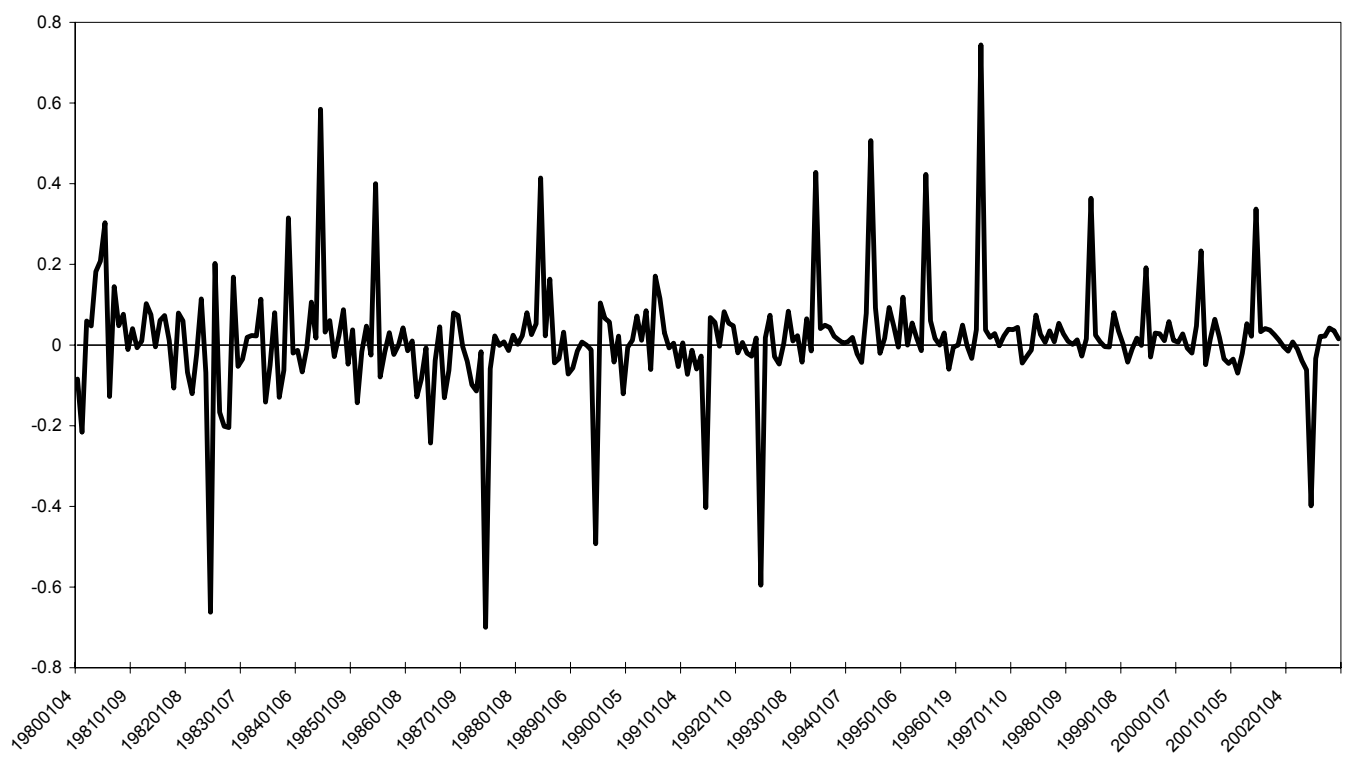

First revisions of nonfarm payrolls headline figure (in percentage points) for the sample period Jan. 1980 until Dec. 2002. Initially released total nonfarm payrolls and first revisions of total nonfarm payrolls are extracted from original announcements of the Bureau of Labor Statistics' employment report. 
Table 1: Nonfarm payroll data used in this study - an example

\begin{tabular}{|c|c|c|c|c|c|c|}
\hline (1) & $(2)$ & (3) & (4) & (5) & (6) & (7) \\
\hline $\begin{array}{c}\text { Release } \\
\text { date }\end{array}$ & $\begin{array}{l}\text { Reported total } \\
\text { prel. estimate } \\
\text { (current month) }\end{array}$ & $\begin{array}{c}\text { nonfarm payrolls } \\
1^{\text {st }} \text { revision } \\
\text { (previous month) }\end{array}$ & $\begin{array}{c}\text { Announced } \\
\text { change } \\
A_{N F}\end{array}$ & $\begin{array}{c}\text { Forecasted } \\
\text { change } \\
F_{N F}\end{array}$ & $\begin{array}{l}\text { Surprise } \\
\qquad S_{N F}\end{array}$ & $\begin{array}{l}\text { Revision } \\
\qquad R_{N F}\end{array}$ \\
\hline $99 / 01 / 08$ & 127.156 & 126.778 & 378 & 200 & 178 & 3 \\
\hline $99 / 02 / 05$ & 127.347 & 127.102 & 245 & 150 & 95 & -54 \\
\hline $99 / 03 / 05$ & 127.610 & 127.335 & 275 & 250 & 25 & -12 \\
\hline $99 / 04 / 02$ & 127.678 & 127.632 & 46 & 163 & -117 & 22 \\
\hline $99 / 05 / 07$ & 127.911 & 127.677 & 234 & 225 & 9 & -1 \\
\hline $99 / 06 / 04$ & 128.167 & 128.156 & 11 & 220 & -209 & 245 \\
\hline
\end{tabular}

Initially reported total nonfarm payrolls $(\times 1,000)$ along with first revisions of the previous months' figures are given in columns 2-3. For example, the May BLS employment report released on June 4, provides a preliminary estimate of May payrolls, i.e. 128,167. The May report also includes a revised April estimate, i.e. 128,156 . The announced nonfarm payrolls headline figure $\left(A_{N F}\right)$ is the change in total payrolls (column 4). This is the difference of the initial May estimate $(128,167)$ and the first revision of the April estimate $(128,156)$. Analysts' median forecasts provided by Standard \& Poors Global Markets (column 5) are used to calculate the unanticipated information (column 6). Such a surprise $\left(S_{N F}\right)$ is given by the deviation of the reported from the forecasted change (e.g. for the May report $S_{N F}=11-220=-209$ ). The revision variable $R_{N F}$ (last column) captures revisions of the previously released total nonfarm payrolls figures. For example, for June $4, R_{N F}$ is calculated as the difference between the revised and the initial April figure (e.g. $\left.R_{N F}=128,156-127,911=245\right)$. 
Table 2: Time series models fitted to historical revisions (1980-2002)

\begin{tabular}{|c|c|c|c|c|c|c|}
\hline & & (1) & $(2)$ & (3) & (4) & (5) \\
\hline \multicolumn{7}{|l|}{$\begin{array}{l}\text { Mean } \\
\text { equation: }\end{array}$} \\
\hline & cons & $0.0144^{* *}$ & $0.0134^{* *}$ & 0.0061 & $0.0123^{* * *}$ & $0.0049^{*}$ \\
\hline & $A R(1)$ & 0.0374 & & $0.0306^{* *}$ & & $0.1836^{* * *}$ \\
\hline \multicolumn{7}{|l|}{$\begin{array}{l}\text { Variance } \\
\text { equation: }\end{array}$} \\
\hline & Cons & & $0.0010^{* * *}$ & $0.0012^{* * *}$ & 0.0025 & -0.0009 \\
\hline & $A R C H(1)$ & & $-0.0406^{* * *}$ & $-0.0412^{* * *}$ & $-0.0011^{* * *}$ & $0.0057^{* * *}$ \\
\hline & $G A R C H(1)$ & & $0.9883^{* * *}$ & $0.9763^{* * *}$ & $0.9800^{* * *}$ & $0.9520^{* * *}$ \\
\hline & $\bar{t}$ & & & & -0.0039 & 0.0028 \\
\hline & $\sin (1 \cdot \bar{t} 2 \pi)$ & & & & -0.0013 & 0.0105 \\
\hline & $\sin (2 \cdot \bar{t} 2 \pi)$ & & & & $-0.0337^{*}$ & -0.0106 \\
\hline & $\sin (3 \cdot \bar{t} 2 \pi)$ & & & & -0.0009 & -0.0002 \\
\hline & $\sin (4 \cdot \bar{t} 2 \pi)$ & & & & $-0.0327^{* * *}$ & $0.0083^{* * *}$ \\
\hline & $\sin (5 \cdot \bar{t} 2 \pi)$ & & & & -0.0008 & $-0.0107^{*}$ \\
\hline & $\cos (1 \cdot \bar{t} 2 \pi)$ & & & & -0.0047 & -0.0072 \\
\hline & $\cos (2 \cdot \bar{t} 2 \pi)$ & & & & 0.0011 & $0.0176^{*}$ \\
\hline & $\cos (3 \cdot \bar{t} 2 \pi)$ & & & & $-0.0381^{* *}$ & $-0.0250 *$ \\
\hline & $\cos (4 \cdot \bar{t} 2 \pi)$ & & & & 0.0006 & $0.0171^{* * *}$ \\
\hline & $\cos (5 \cdot \bar{t} 2 \pi)$ & & & & $-0.0707^{* * *}$ & -0.0099 \\
\hline & $\chi_{L R}^{2}$ & & & & $326,9914^{* * *}$ & $322,1456^{* * *}$ \\
\hline & LL & 154.7944 & 179.1398 & 176.0257 & 342.6355 & 337.0985 \\
\hline & $\mathrm{AIC}$ & 1.1153 & 1.2737 & 1.2484 & 2.3828 & 2.3438 \\
\hline & B/G LM & 14.9745 & 15.3290 & 14.9190 & 15.3600 & $20.0216^{*}$ \\
\hline & ARCH LM & $43.9773^{* * *}$ & $73.3178^{* * *}$ & $64.8624^{* * *}$ & 8.6484 & 13.3781 \\
\hline
\end{tabular}

Estimated time series models for revisions in the nonfarm payrolls. The sample period is 1/1980 - 12/2002 (264 observations). The conditional mean function includes a constant and an AR(1) term, the conditional variance function includes one $\mathrm{ARCH}$ and one $\mathrm{GARCH}$ term. Moreover, in both the conditional mean and conditional variance function flexible Fourier transforms of order $Q=5$ are included to account for seasonal patterns (see eq. 10). The joint-significance of the seasonality coefficients is tested via a likelihood ratio test $\left(\chi_{L R}^{2}\right)$. For each model, the log likelihood (LL) is reported. The goodness-of-fit of the models is evaluated according to the Akaike information criterion (AIC). The last two lines report statistics of LM tests against autocorrelation in the residuals according to Breusch and Godfrey (B/G) and results of LM test against ARCH effects (see, Engle 1982). Both types of LM tests are based on 12 lags, i.e. one year. ${ }^{* * *},{ }^{* *}$, and ${ }^{*}$ indicates significance at the $1 \%, 5 \%$, and $10 \%$ level, respectively. 
Table 3: Price impact of unanticipated information dependent on the relative precision

\begin{tabular}{|c|c|c|c|c|c|}
\hline & & $(1)$ & $(2)$ & $(3)$ & $(4)$ \\
\hline \multicolumn{6}{|l|}{ Mean equation } \\
\hline Cons & $\beta_{0}$ & -0.005 & -0.005 & -0.005 & -0.006 \\
\hline$A R(1)$ & $\beta_{1}$ & $-0.089^{* * *}$ & $-0.090 * * *$ & $-0.091 * * *$ & $-0.089 * * *$ \\
\hline$A R(2)$ & $\beta_{2}$ & 0.004 & 0.004 & 0.003 & \\
\hline$S_{N F, t-1}$ & $\beta_{3}$ & $-3.044^{*}$ & $-2.977^{* *}$ & $-2.943^{* *}$ & $-2.823^{* *}$ \\
\hline$S_{N F, t}$ & $\beta_{4}$ & $-27.155^{* * *}$ & & & \\
\hline$S_{N F, t} \times D^{\rho l o w}$ & $\beta_{4}^{\ell}$ & & $-23.171^{* * *}$ & $-23.185^{* * *}$ & $-22.784^{* * *}$ \\
\hline$S_{N F, t} \times D^{\rho h i g h}$ & $\beta_{4}{ }^{h}$ & & $-32.048 * * *$ & $-31.783^{* * *}$ & $-32.788 * * *$ \\
\hline$S_{N F, t+1}$ & $\beta_{5}$ & $-5.192^{* *}$ & $-4.971^{* *}$ & & \\
\hline$S_{N F, t+1} \times D^{\rho l o w}$ & $\beta_{5}^{\ell}$ & & & -2.086 & -2.726 \\
\hline$S_{N F, t+1} \times D^{\rho h i g h}$ & $\beta_{5}^{h}$ & & & $-8.484^{* * *}$ & $-8.666^{* * *}$ \\
\hline$S_{U N, t-1}$ & $\beta_{6}$ & -0.402 & -0.483 & -0.485 & \\
\hline$S_{U N, t}$ & $\beta_{7}$ & $8.926^{* * *}$ & $9.082^{* * *}$ & $9.094^{* * *}$ & $9.686^{* * *}$ \\
\hline$S_{U N, t+1}$ & $\beta_{8}$ & 1.087 & 1.115 & 1.249 & \\
\hline$R_{N F, t-1}$ & $\beta_{9}$ & 2.328 & 2.061 & 2.078 & \\
\hline$R_{N F, t}$ & $\beta_{10}$ & -5.268 & -5.068 & -5.113 & \\
\hline$R_{N F, t+1}$ & $\beta_{11}$ & -0.549 & -0.634 & -0.524 & \\
\hline \multicolumn{6}{|c|}{ Variance equation } \\
\hline Cons & $\omega_{0}$ & $0.298 * * *$ & $0.299^{* * *}$ & $0.298^{* * *}$ & $0.302^{* * *}$ \\
\hline$A R C H(1)$ & $\phi_{1}$ & $0.118^{* * *}$ & $0.119^{* * *}$ & $0.119^{* * *}$ & $0.110^{* * *}$ \\
\hline$A R C H(2)$ & $\phi_{2}$ & $0.055^{* * *}$ & $0.055^{* * *}$ & $0.055^{* * *}$ & $0.054^{* * *}$ \\
\hline$A R C H(3)$ & $\phi_{3}$ & $0.036^{* *}$ & $0.036^{* *}$ & $0.037^{* *}$ & $0.035^{* *}$ \\
\hline $\mathrm{R}$-sq. & & 0.2370 & 0.2404 & 0.2425 & 0.2328 \\
\hline $\mathrm{LL}$ & & -6157.97 & -6153.50 & -6151.66 & -6166.42 \\
\hline $\mathrm{AIC}$ & & -2.1476 & -2.1464 & -2.1461 & -2.1491 \\
\hline \multicolumn{6}{|l|}{ LR-tests } \\
\hline \multirow[t]{2}{*}{$H_{0}: \beta_{4} \geq-\beta_{7}$} & & $80.7879 * * *$ & & & \\
\hline & & $(-6198.36)$ & & & \\
\hline \multirow[t]{2}{*}{$H_{0}: \beta_{4}{ }^{h} \geq \beta_{4}{ }^{\ell}$} & & & $8.9381^{* * *}$ & $8.6106^{* * *}$ & $11.4608^{* * *}$ \\
\hline & & & $(-6157.97)$ & $(-6155.96)$ & $(-6172.16)$ \\
\hline \multirow[t]{2}{*}{$H_{0}: \beta_{5}{ }^{h} \geq \beta_{5}{ }^{\ell}$} & & & & $3.6828^{* *}$ & $3.0753^{* *}$ \\
\hline & & & & $(-6153.50)$ & $(-6167.96)$ \\
\hline
\end{tabular}

QML estimation of $\mathrm{AR}(2)-\mathrm{ARCH}(3)$ models for 2-min log returns during the intraday interval 8:22-9:52 a.m. EST at employment announcement days for which no other macroeconomic report is released at the same time. The sample period is Jan. 1991 - Dec. 2002, resulting in 5760 observations (i.e. 128 days with no overlapping announcements $\times 452$-min intervals). The conditional variance equations also include seasonal components as described in eq. (10), i.e. flexible Fourier transforms of order $Q=5$, whose estimated coefficients are omitted here. For each model, the R-Squared, the log likelihood (LL), and the Akaike information criterion (AIC) are reported. In addition, $\chi^{2}$ statistics of LR tests on the inequality of selected parameters are given at the bottom (log likelihood of restricted models in parenthesis). Inference is based on QML standard errors (Bollerslev and Wooldridge 1992). ${ }^{* * *},{ }^{* *}$, and ${ }^{*}$ indicates significance at the $1 \%$, $5 \%$, and $10 \%$ level, respectively. Except for the LR tests, the level of significance is based on two-sided tests. 
Table 4: Asymmetric price impact of 'good' news versus 'bad' news?

\begin{tabular}{|c|c|c|c|c|c|}
\hline & & $(5)$ & (6) & (7) & $(8)$ \\
\hline \multicolumn{6}{|l|}{ Mean equation } \\
\hline Cons & & -0.006 & -0.006 & -0.004 & -0.004 \\
\hline$A R(1)$ & & $-0.088^{* * *}$ & $-0.089 * * *$ & $-0.088^{* * *}$ & $-0.088 * * *$ \\
\hline$S_{N F, t-1}$ & & $-2.975^{* *}$ & $-2.823^{* *}$ & $-2.814^{* *}$ & $-2.921^{* *}$ \\
\hline$S_{N F, t}$ & $\beta_{4}$ & $-27.362^{* * *}$ & & & \\
\hline$S_{N F, t} \times D^{\pi l o w}$ & $\beta_{4}^{\ell}$ & & $-22.784^{* * *}$ & & \\
\hline$S_{N F, t} \times D^{\pi h i g h}$ & $\beta_{4}^{h}$ & & $-32.789 * * *$ & & \\
\hline$S_{N F, t} \times D^{g o o d}$ & $\beta_{4}{ }^{g}$ & & & $-22.184^{* * *}$ & \\
\hline$S_{N F, t} \times D^{b a d}$ & $\beta_{4}{ }^{b}$ & & & $-35.764 * * *$ & \\
\hline$S_{N F, t} \times D^{\pi l o w} \times D^{\text {good }}$ & $\beta_{4}^{\ell, g}$ & & & & $-19.107^{* * *}$ \\
\hline$S_{N F, t} \times D^{\pi h i g h} \times D^{g o o d}$ & $\beta_{4}^{\ell, b}$ & & & & $-26.126^{* * *}$ \\
\hline$S_{N F, t} \times D^{\pi l o w} \times D^{b a d}$ & $\beta_{4}{ }^{h, g}$ & & & & $-29.648^{* * *}$ \\
\hline$S_{N F, t} \times D^{\pi h i g h} \times D^{b a d}$ & $\beta_{4}^{h, b}$ & & & & $-41.487^{* * *}$ \\
\hline$S_{N F, t+1} \times D^{\pi l o w}$ & & -2.660 & -2.726 & -2.900 & -2.901 \\
\hline$S_{N F, t+1} \times D^{\pi h i g h}$ & & $-8.892^{* * *}$ & $-8.666^{* * *}$ & $-7.789^{* * *}$ & $-7.279^{* * *}$ \\
\hline$S_{U N, t}$ & & $9.559^{* * *}$ & $9.686^{* * *}$ & $9.217 * * *$ & $9.333^{* * *}$ \\
\hline \multicolumn{6}{|l|}{ Variance equation } \\
\hline Cons & & $0.302^{* * *}$ & $0.302^{* * *}$ & $0.301^{* * *}$ & $0.301^{* * *}$ \\
\hline$A R C H(1)$ & & $0.108^{* * *}$ & $0.110^{* * *}$ & $0.112^{* * *}$ & $0.113^{* * *}$ \\
\hline$A R C H(2)$ & & $0.054^{* * *}$ & $0.054^{* * *}$ & $0.055^{* * *}$ & $0.054^{* * *}$ \\
\hline$A R C H(3)$ & & $0.035^{* *}$ & $0.035^{* *}$ & $0.036^{* *}$ & $0.036^{* *}$ \\
\hline R-sq. & & 0.2287 & 0.2328 & 0.2350 & 0.2384 \\
\hline LL & & -6172.16 & -6166.42 & -6162.03 & -6156.96 \\
\hline $\mathrm{AIC}$ & & -2.1507 & -2.1491 & -2.1476 & -2.1465 \\
\hline \multicolumn{6}{|l|}{ LR-test } \\
\hline \multirow[t]{2}{*}{$H_{0}: \beta_{4}{ }^{h, \cdot} \geq \beta_{4}{ }^{\ell, \cdot}$} & & & $11.4608^{* * *}$ & & $10.1299^{* * *}$ \\
\hline & & & $(-6172.16)$ & & $(-6162.03)$ \\
\hline \multirow[t]{2}{*}{$H_{0}: \beta_{4} \cdot, b \geq \beta_{4} \cdot, g$} & & & & $20.2563^{* * *}$ & $18.9254^{* * *}$ \\
\hline & & & & $(-6172.16)$ & $(-6166.42)$ \\
\hline
\end{tabular}

Re-estimation of the parsimonious specification (4) given in Table 3 in order to analyze a possibly asymmetric price impact of 'good' and 'bad' news. Model (5) is a simplification of model (4) since it ignores both precision and 'bad' news effects. Model (6) is identical to model (4). It accounts for differential information precision by interacting the regressor capturing the immediate price impact of unanticipated information in the nonfarm payrolls figure, $S_{N F, t}$, with dummy variables capturing the precision of this information $\left(D^{\pi l o w}\right.$ and $\left.D^{\pi h i g h}\right)$. In model (7) $S_{N F, t}$ is interacted with dummy variables which indicate whether a surprise provides 'good' news for the bond market (i.e. $D^{\text {good }}=1$ if $S_{N F}<0$ ) or 'bad' news (i.e. $D^{\text {bad }}=1-D^{\text {good }}$ ). Model (8) accounts for both precision and 'bad' vs. 'good' news effects. All other variables remain unchanged. Parameter estimates of flexible Fourier transforms $(Q=5)$ are omitted. $\chi^{2}$ statistics of one-sided LR tests are given at the bottom (log likelihood of restricted model in parenthesis). Inference is based on QML standard errors (Bollerslev and Wooldridge 1992). ${ }^{* * *},{ }^{* *}$, and ${ }^{*}$ indicates significance at the $1 \%, 5 \%$, and $10 \%$ level, respectively. Except for the LR tests, significance is based on two-sided tests. 